\title{
A TWO PHASED FUZZY METHODOLOGY FOR SELECTION AMONG MUNICIPAL PROJECTS
}

\author{
Mehmet Emin BAYSAL ${ }^{a}$, İhsan KAYA ${ }^{b}$, Cengiz KAHRAMAN ${ }^{c}$, \\ Ahmet SARUCAN ${ }^{a}$, Orhan ENGIN ${ }^{a}$ \\ ${ }^{a}$ Department of Industrial Engineering, Selcuk University, Konya, Turkey \\ ${ }^{b}$ Department of Industrial Engineering, Yildiz Technical University, Istanbul, Turkey \\ 'Department of Industrial Engineering, Istanbul Technical University, Istanbul, Turkey
}

Received 17 January 2012; accepted 20 January 2013

\begin{abstract}
A municipality improves the quality of community life through its projects and actions. However, project selection and prioritization by municipalities are highly complex processes. Therefore, multicriteria decision making (MCDM) methodologies are very suitable for determining the best alternative. Recently, some studies have concentrated on the selection of the best project alternatives. In this paper, a two phased fuzzy MCDM methodology is proposed for the selection among municipal projects. In the first phase, fuzzy TOPSIS method is used to select the main project group and then fuzzy AHP is used to select the best sub-municipal project. The application of the suggested methodology has been made at the central district municipality in Konya, Turkey.
\end{abstract}

Keywords: integrated fuzzy methodology, fuzzy TOPSIS, fuzzy AHP, municipal project selection.

JEL Classification: D81, H43, O22, R11.

\section{Introduction}

The main policy of a municipality, which includes specifically the regeneration of cities, is constituted according to sustainable economic and social development, and environmental protection. Municipalities are the core administrative units they are endowed with an extensive planning autonomy. On the contrary municipalities have limited resources and need to decide which projects will be benefited at most. The municipal projects are prepared by analyzing the needs of the city and the expectations of city residents. Project selection process of a muni-

Corresponding author İhsan Kaya

E-mails: ihkaya@yildiz.edu.tr;iekaya@yahoo.com 
cipality includes prioritizing the allocation of resources. The general structure of a municipal project selection process is depicted in Figure 1. The vision, mission, and strategic objectives must be taken into consideration for the municipal projects.

The municipal project selection (MPS) problem is a multi-criteria decision making problem. According to our knowledge, this is the first study for the multi-criteria selection among municipal projects with a fuzzy methodology. The goals of the decision problem for (MPS) can be given as follows:

- All local actors are encouraged for the participation into the municipal services;

- All staff are encouraged for the participation into the municipal services;

- To give the service just in time and in quality for the residents;

- To provide for residents quality living area;

- To provide for residents healthy and clean environment and modernly designed landscape.

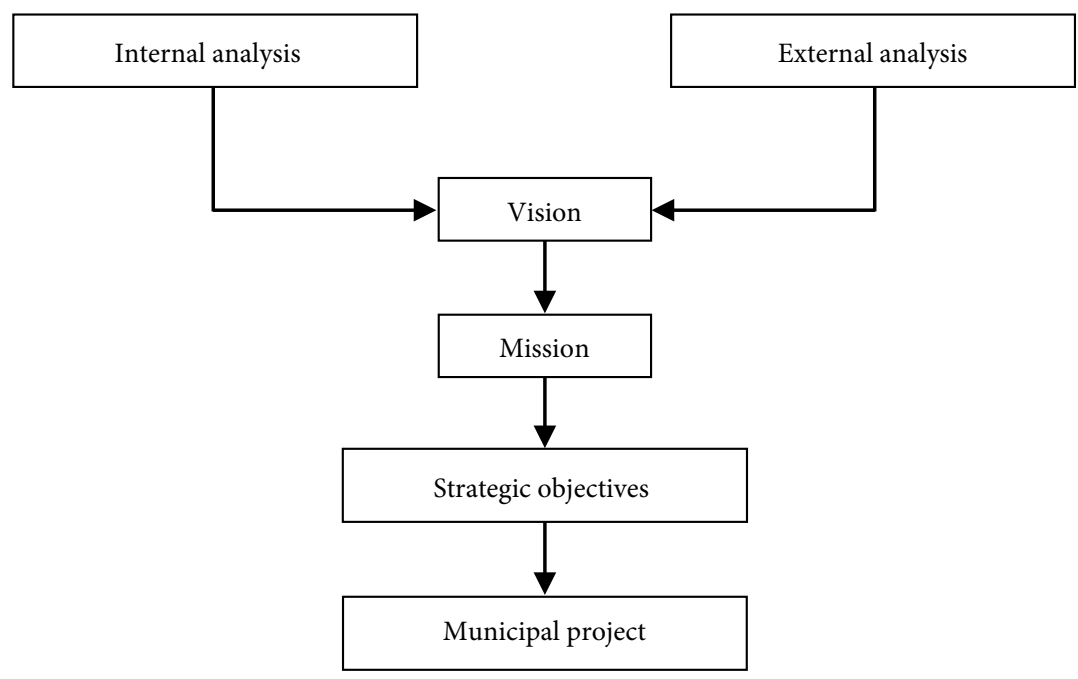

Fig. 1. Municipal project process

The selection among municipal projects is a multi-criteria problem with many conflicting criteria. Moreover, these criteria can be objective or subjective. These kinds of criteria make the evaluation process hard and vague. On the other hand, it is difficult to take the assessments of decision makers on alternatives with respect to the related criteria precisely. In many decision making problems, the decision makers (DM) define their preferences in linguistic form since it is relatively difficult to provide exact numerical values during the evaluation of alternatives. Therefore, in many studies, fuzzy logic is successfully used to model this type of uncertainty. Fuzzy logic, proposed by Zadeh in 1965, is a matter of the fuzzy set theory particularly used for dealing with imprecise information.

The aim of this paper is to propose a fuzzy multi-criteria model for selection among the municipal projects. A two phased fuzzy methodology is used in this proposal. In the first 
phase, fuzzy TOPSIS method is used to select the main project group and then fuzzy AHP is used to select the best sub-municipal project. An application is made at the central district municipality in Konya, Turkey.

The rest of this paper is organized as follows. The literature review and the proposed methodologies are given in Section 1. In Section 2, the municipal projects alternatives for Konya and selection criteria are presented. The proposed fuzzy TOPSIS and fuzzy AHP methodology are applied for these project alternatives and a sensitivity analysis is managed in Section 3 . The conclusion, obtained results and suggestions for further research are discussed in final section.

\section{The proposed methodologies and related literature}

In this study, a fuzzy TOPSIS method is used to select the main project group and then fuzzy AHP is used to select the best sub-municipal project. In recent years some studies on fuzzy TOPSIS and fuzzy AHP have concentrated on selection problems. These are summarized in the following.

\subsection{Fuzzy TOPSIS}

TOPSIS is a multi-criteria decision-making technique to rank different alternatives through numerical evaluations the decision maker performs with respect to certain criteria. Weights can also be specified for each criterion, in order to introduce a measure of the relative importance felt by the decision maker (Gamberini et al. 2006; Kahraman et al. 2009b). The method is based on the consideration that the chosen alternative should have the shortest distance from the positive-ideal solution and the farthest distance from the negative ideal solution. TOPSIS defines an index called similarity to the positive-ideal solution and remoteness from the negative-ideal solution. Then the method chooses an alternative with the maximum similarity to the ideal solution (Yoon, Hwang 1995). The Fuzzy set theory resembles human reasoning in its use of approximate information and uncertainty to generate decisions. It was specifically designed to mathematically represent uncertainty and vagueness and provide formalized tools for dealing with the imprecision intrinsic to many problems. By contrast, traditional computing demands precision down to each bit. Since knowledge can be expressed in a more natural way by using fuzzy sets, many engineering and decision problems can be greatly simplified. The decision maker can specify preferences in the form of natural language expressions about the importance of each criterion (Kahraman et al. 2004a). In this study fuzzy TOPSIS approach is used to specify the ranking of alternatives according to aggregated decision matrix and weight vector as well as the individual decision matrices and weigh vectors.

Fuzzy TOPSIS (FTOPSIS) was first presented in Chen and Hwang (1992), with reference to Hwang and Yoon (1981). The basic principle of the fuzzy TOPSIS is that the chosen alternative should have the shortest distance from the positive ideal solution and the farthest distance from the negative-ideal solution in a geometrical (i.e. Euclidean) sense (Hwang, Yoon 1981).

The TOPSIS method has been used for some municipality projects in recent years. For example, Sadeghi-Moghaddam et al. (2011) considered urban development strategy by taking 
into account public participation, local government power and urban vision. They tried to explain and define criteria's such as development strategy plan and urban management. The TOPSIS method had been used for this aim. Xiao and Yang (2011) determined the assessing index of the regional innovation capacity on 30 municipalities by using TOPSIS.

The steps of fuzzy TOPSIS can be summarized as follows (Chen 2000; Aydin et al. 2012):

Step 1: Form a committee of decision-makers, and then identify the evaluation criteria.

Step 2: Choose the appropriate linguistic variables for the importance weight of the criteria and the linguistic ratings for alternatives with respect to criteria. For this aim, Tables 1 and 2 can be used.

Table 1. Linguistic variables for the importance weight of each criterion

\begin{tabular}{ll}
\hline Very low $(\mathrm{VL})$ & $(0.0,0.0,0.1)$ \\
\hline Low $(\mathrm{L})$ & $(0.0,0.1,0.3)$ \\
\hline Medium low $(\mathrm{ML})$ & $(0.1,0.3,0.5)$ \\
\hline Medium $(\mathrm{M})$ & $(0.3,0.5,0.7)$ \\
\hline Medium high $(\mathrm{MH})$ & $(0.5,0.7,0.9)$ \\
\hline High $(\mathrm{H})$ & $(0.7,0.9,1.0)$ \\
\hline Very high $(\mathrm{VH})$ & $(0.9,1.0,1.0)$ \\
\hline
\end{tabular}

Table 2. Linguistic variables for the ratings

\begin{tabular}{ll}
\hline Very poor (VP) & $(0,0,1)$ \\
\hline Poor (P) & $(0,1,3)$ \\
\hline Medium poor (MP) & $(1,3,5)$ \\
\hline Fair (F) & $(3,5,7)$ \\
\hline Medium good (MG) & $(5,7,9)$ \\
\hline Good (G) & $(7,9,10)$ \\
\hline Very good (VG) & $(9,10,10)$ \\
\hline
\end{tabular}

Step 3: Pool the decision makers' opinions to get the aggregated fuzzy rating $\tilde{x}_{i j}$ of alternative $A_{i}$ under criterion $C_{j}$ and aggregate the weights of criteria to get the aggregated fuzzy weight $\tilde{w}_{j}$ of criterion $C_{j}$ by using Eqs (1) and (2), respectively.

$$
\begin{aligned}
& \tilde{x}_{i j}=\frac{1}{K}\left[\tilde{x}_{i j}^{1}(+) \tilde{x}_{i j}^{2}(+) \cdots(+) \tilde{x}_{i j}^{K}\right] ; \\
& \tilde{w}_{j}=\frac{1}{K}\left[\tilde{w}_{j}^{1}(+) \tilde{w}_{j}^{2}(+) \cdots(+) \tilde{w}_{j}^{K}\right],
\end{aligned}
$$

where $K$ is the number of decision makers, $\tilde{x}_{i j}^{K}$ and $\tilde{w}_{j}^{K}$ are the rating and the importance weight of the $K^{\text {th }}$ decision maker.

Step 4: Construct the fuzzy decision matrix and the normalized fuzzy decision matrix as in Eqs (3) and (4).

$$
\tilde{R}=\left[\tilde{r}_{i j}\right]_{m^{*} n}
$$




$$
\begin{aligned}
& \tilde{r}_{i j}=\left(\frac{a_{i j}}{c_{j}^{*}}, \frac{b_{i j}}{c_{j}^{*}}, \frac{c_{i j}}{c_{j}^{*}}\right), j \in B ; \\
& \tilde{r}_{i j}=\left(\frac{a_{j}^{-}}{c_{i j}}, \frac{a_{j}^{-}}{b_{i j}}, \frac{a_{j}^{-}}{a_{i j}}\right), j \in C ; \\
& c_{j}^{*}=\max _{i} c_{i j} \text { if } j \in B ; \\
& a_{j}^{-}=\min _{i} a_{i j} \text { if } j \in C,
\end{aligned}
$$

where $B$ and $C$ are the set of benefit criteria and cost criteria, respectively,

Step 5: Construct the weighted normalized fuzzy decision matrix by Eqs (5) and (6).

$$
\begin{aligned}
& \tilde{V}=\left[\tilde{v}_{i j}\right]_{m \times n} ; \\
& \tilde{v}_{i j}=\tilde{r}_{i j} \otimes \tilde{w}_{j} .
\end{aligned}
$$

Step 6: Determine FPIS and FNIS.

Step 7: Calculate the distances of each alternative from the fuzzy positive-ideal solution (FPIS, $A^{\star}$ ) and the fuzzy negative-ideal solution (FNIS, A-) as in Eq. (7), respectively.

$$
\begin{aligned}
& A^{*}=\left(\tilde{v}_{1}^{*}, \tilde{v}_{2}^{*}, \ldots, \tilde{v}_{n}^{*}\right) ; \\
& A^{-}=\left(\tilde{v}_{1}^{-}, \tilde{v}_{2}^{-}, \ldots, \tilde{v}_{n}^{-}\right) .
\end{aligned}
$$

Step 8: Calculate the closeness coefficient of each alternative as in Eq. (8).

$$
\begin{aligned}
& d_{i}^{*}=\sum_{j=1}^{n} d\left(\tilde{v}_{i j}, \tilde{v}_{i j}^{*}\right), i=1,2, \ldots, m ; \\
& d_{i}^{-}=\sum_{j=1}^{n} d\left(\tilde{v}_{i j}, \tilde{v}_{i j}^{-}\right), i=1,2, \ldots, m,
\end{aligned}
$$

where $d\left(d_{i}^{*}, d_{i}^{-}\right)$is the distance measurement between two fuzzy numbers.

Then a closeness coefficient is defined to determine the ranking order of all alternatives as in Eq. (9).

$$
C C_{i}=\frac{d_{i}^{-}}{d_{i}^{*}+d_{i}^{-}}, i=1,2, \ldots, m .
$$

Step 9: According to the closeness coefficient, the ranking order of all alternatives can be determined.

\subsection{Fuzzy AHP}

AHP is developed to solve complex MCDM problems involving multiple qualitative and quantitative criteria. It is very useful for handling multiple criteria and objectives in the decision-making problems. It allows decision-makers to specify their preferences using the Saaty's 1-9 scale (Saaty 1980). This scale can be very useful in helping a group of experts or 
an individual to make a decision. The purpose of AHP is to provide weights for each criterion and alternatives. AHP requires three steps: (1) identifying evaluation criteria; (2) assessing the decision-maker evaluations by pairwise comparisons; and (3) calculating the weights for criteria and alternatives. In AHP, logical consistency is also considered by evaluating the validity of the pairwise comparison process obtained from decision-makers' preferences. Since the fuzzy set theory successfully represents human reasoning in its use of approximate information and uncertainty to generate decisions, the fuzzy-AHP methodology is used in this paper.

The AHP method has been used for some municipality projects in recent years. Kaya (2012) analyzed an outsourcing decision for the management of WEEE by using a fuzzy multicriteria decision making approach based on fuzzy AHP. Kılıç (2011) presented a fuzzy AHP based performance assessment system for determining the importance weights of factors in the strategic plan of Turkish municipalities. Kahraman and Kaya (2010) suggested a fuzzy multicriteria decision-making methodology for the selection among energy policies. The methodology was based on the analytic hierarchy process (AHP) under fuzziness. Kahraman et al. (2009a) suggested fuzzy axiomatic design and fuzzy analytic hierarchy process for the selection among renewable energy alternatives. Mahmoodzadeh et al. (2007) proposed a new method for project selection problem by using fuzzy AHP and TOPSIS technique. Zeng et al. (2007) described an innovative systematic approach, namely hierarchy grey relational analysis for optimal selection of wastewater treatment alternatives, based on the application of AHP and grey relational analysis (GRA).

In this paper, Buckley's (1985) fuzzy AHP method is used. The steps of fuzzy AHP are summarized as following (Kahraman et al. 2013):

Step 1: Pairwise comparison matrices are constructed. Each element $\left(\tilde{c}_{i j}\right)$ of the pairwise comparison matrix $(\mathrm{C})$ is a linguistic term representing the importance of one criterion over the other. The pairwise comparison matrix is given by:

$$
\tilde{C}_{k}=\left|\begin{array}{cccc}
1 & \tilde{c}_{12} & \ldots & \tilde{c}_{1 n} \\
\tilde{c}_{21} & 1 & \ldots & \tilde{c}_{2 n} \\
\vdots & \vdots & \ldots \vdots & \vdots \\
\tilde{c}_{n 1} & \tilde{c}_{n 2} & \ldots & 1
\end{array}\right|, k=1,2,3, \ldots, K,
$$

where $\tilde{C}_{k}$ is a pairwise comparison matrix belongs to $k^{\text {th }}$ expert for $F R m$. For the evaluation procedure, the linguistic terms given in Table 3 are used. Geometric mean is used to aggregate expert opinions.

Table 3. Linguistic scale for weight matrix

\begin{tabular}{cll}
\hline Linguistic scales & Scale of fuzzy number & \\
\hline$(1,1,3)$ & Equally important & $(\mathrm{Eq})$ \\
\hline$(1,3,5)$ & Weakly important & $(\mathrm{Wk})$ \\
\hline$(3,5,7)$ & Essentially important & $(\mathrm{Es})$ \\
\hline$(5,7,9)$ & Very strongly important & $(\mathrm{Vs})$ \\
\hline$(7,9,9)$ & Absolutely important & $(\mathrm{Ab})$ \\
\hline
\end{tabular}

Source: Hsieh et al. (2004). 
Step 2: Weights are calculated. At first, the fuzzy weight matrix is calculated by Buckley's Method as follows (Hsieh et al. 2004):

$$
\begin{aligned}
& \tilde{r}_{i}=\left(\tilde{c}_{i 1} \otimes \tilde{c}_{i 2} \otimes \ldots \otimes \tilde{c}_{i n}\right)^{1 / n} ; \\
& \tilde{w}_{i}=\tilde{r}_{i} \otimes\left(\tilde{r}_{1}+\tilde{r}_{2}+\ldots+\tilde{r}_{n}\right)^{-1},
\end{aligned}
$$

where $\tilde{r}_{i}$ is the geometric mean of fuzzy comparison value and $\tilde{w}_{i}$ indicated by triangular fuzzy numbers $\tilde{w}_{i}\left(L_{i}, M_{i}, U_{i}\right)$ is fuzzy weight of $i^{\text {th }}$ criterion.

Step 3: After the fuzzy relative weight matrix is obtained, defuzzification process which converts a fuzzy number into a crisp value is utilized. In this paper, the total integral method is used for this aim. Liou and Wang (1992) proposed the total integral value method with an index of optimism $\omega \in[0,1]$. Let $\tilde{A}$ be a fuzzy number with left membership function $f_{\tilde{A}}^{L}$ and right membership function $f_{\tilde{A}}^{R}$. Then the total integral value is defined as (Kahraman et al. 2004b):

$$
E_{\omega}(\tilde{A})=\omega E_{R}(\tilde{A})+(1-\omega) E_{L}(\tilde{A})
$$

where:

$$
E_{R}(\tilde{A})=\int_{\alpha}^{\beta} x f_{\tilde{A}}^{R}(x) d x
$$

and

$$
E_{L}(\tilde{A})=\int_{\gamma}^{\delta} x f_{\tilde{A}}^{L}(x) d x,
$$

where: $-\infty<\alpha \leq \beta \leq \gamma \leq \delta<\infty$. For a triangular fuzzy number, $\tilde{A}=(a, b, c)$, the total integral value is obtained by:

$$
E_{\omega}(\tilde{A})=\frac{1}{2}[\omega(a+b)+(1-\omega)(b+c)] .
$$

\section{Municipal projects}

The municipal projects aim at solving the problems related to critical water, wastewater, and solid waste investments that will help bring safer water, more sanitary landfills and a clean environment to people living in cities. Main projects groups are composed of urban development projects, social support projects, human resources projects, financial resources projects, environmental projects, disaster projects, information projects, cultural projects, cultural projects and city and social order projects. Every main municipal project has its own sub-municipal projects. The possible main and sub-municipal projects can be classified as in Table 4.

In Section 3, the main-municipal projects in Table 4 that are the alternatives for the first selection phase are evaluated. After one of these main groups is selected by fuzzy TOPSIS, one of the sub-municipal projects of the selected main group is selected by using fuzzy AHP. 
Table 4. Main and sub-municipal projects

\begin{tabular}{|c|c|}
\hline Main municipal projects & Sub-municipal projects \\
\hline \multirow{4}{*}{$\begin{array}{l}\text { 1. Urban development projects } \\
\text { (MMP1) }\end{array}$} & 1.1. Projects for infrastructure \\
\hline & 1.2. Projects for urban transformation \\
\hline & 1.3. Projects for supporting aesthetical aspects of the city \\
\hline & 1.4. Projects for enabling housing audits \\
\hline \multirow{2}{*}{$\begin{array}{l}\text { 2. Social support projects } \\
\text { (MMP2) }\end{array}$} & 2.1. Projects for vocational course activities \\
\hline & $\begin{array}{l}\text { 2.2. Projects for strengthening cooperation with stakeholders and } \\
\text { volunteers on social support services. }\end{array}$ \\
\hline \multirow{2}{*}{$\begin{array}{l}\text { 3. Human resources projects } \\
\text { (MMP3) }\end{array}$} & 3.1. Projects for developing performance oriented work approach \\
\hline & 3.2. Projects for establishing and extending proposal system \\
\hline \multirow[t]{3}{*}{$\begin{array}{l}\text { 4. Financial resources projects } \\
\text { (MMP4) }\end{array}$} & $\begin{array}{l}\text { 4.1. Projects for enabling information technology utilization for } \\
\text { financial services }\end{array}$ \\
\hline & 4.2. Projects for managing resources effectively \\
\hline & 4.3. Projects for managing real estate revenues efficiently \\
\hline \multirow{3}{*}{$\begin{array}{l}\text { 5. Environmental projects } \\
\text { (MMP5) }\end{array}$} & 5.1. Projects for waste management \\
\hline & 5.2. Projects for extending green zones \\
\hline & 5.3. Projects for strengthening cooperation with stakeholders. \\
\hline \multirow[t]{3}{*}{ 6. Disaster projects (MMP6) } & 6.1. Projects for increasing the capacity for disaster .response \\
\hline & 6.2. Projects for raise awareness for disasters \\
\hline & $\begin{array}{l}\text { 6.3. Projects for strengthening cooperation with stakeholders } \\
\text { and volunteers in disasters }\end{array}$ \\
\hline \multirow[t]{2}{*}{$\begin{array}{l}\text { 7. Information projects } \\
\text { (MMP7) }\end{array}$} & $\begin{array}{l}\text { 7.1. Projects for developing the services level of information } \\
\text { and communication systems }\end{array}$ \\
\hline & 7.2. Projects for e-municipality practices. \\
\hline \multirow[t]{2}{*}{ 8. Cultural projects(MMP8) } & 8.1. Projects for protection of cultural and natural assets. \\
\hline & 8.2. Projects for cultural tourism activities \\
\hline \multirow{2}{*}{$\begin{array}{l}\text { 9. City and social order } \\
\text { projects (MMP9) }\end{array}$} & 9.1. Projects for environment protection \\
\hline & 9.2. Projects for city aesthetics \\
\hline
\end{tabular}

\section{A real case application}

The proposed methodology is applied at the central district municipality in Konya, Turkey where is located in the central region of Turkey. Its territory covers $38,873 \mathrm{~km}^{2}$ and is the largest city of the Turkey. The city Konya is bordered by the cities Aksaray, Ankara, Niğde, İçel, Karaman, Antalya, Isparta, Afyon and Eskişehir. In 2009 Konya population was $1,992,675$ (TUIK 2010). Its annual population growth rate is $11.51 \%$. Accordingly, the population density of the city is 51 persons per square kilometer (TUIK 2010). Konya Municipal Administration is composed of four municipalities; namely Municipality of Selçuklu, Municipality of Karatay, Municipality of Meram, and Metropolitan Municipality. 
In this paper a real set of projects for Konya is considered. The names of these projects can be seen in Table 4. The considered project alternatives are based on the 2010-2014 Strategic Plan periodfor Konya. The project alternatives are determined by a decision making group that consist of 16 decision makers from the municipality, universities, and non-governmental organizations. The emands and expectations of people of Konya are evaluated using a questionnaire. Complaints of people about the municipality are collected by e-mail, telephone, etc. Then the main and sub-municipal projects are determined by the decision making group. This group determined the following strategic areas for possible projects:

- Urban development;

- Social support;

- Human resources;

- Financial resources;

- Environmental;

- Disaster;

- Information;

- Cultural and social order.

These strategic areas are taken into account as main municipal projects in our paper. The activities for these areas are also taken into account as sub-municipal projects.

The seven criteria, as given in Table 5, are identified for decision-making on municipal projects (Smith-Perera et al. 2010).

Table 5. Criteria used for the selection among municipal projects

\begin{tabular}{ll}
\hline \multicolumn{1}{c}{ Criteria } & \multicolumn{1}{c}{ Explanation } \\
\hline 1. Meeting societal needs (MSN) & $\begin{array}{l}\text { It refers to that allows comparison between projects in } \\
\text { terms on whether the project expects the residents or not. }\end{array}$ \\
\hline 2. Resident's satisfaction (RS) & $\begin{array}{l}\text { It refers to that allows comparisons between solutions in } \\
\text { terms on the impact on the residents' perception seen by } \\
\text { the decision maker. }\end{array}$ \\
\hline 3. Staff satisfaction (SS) & $\begin{array}{l}\text { It refers to that allows comparison between projects in } \\
\text { terms on whether the staff likes the project or not. }\end{array}$ \\
\hline 4. Project completion times (PCT) & $\begin{array}{l}\text { It refers to that compares projects in terms of needs time to } \\
\text { plan the project, develop it and make installation. }\end{array}$ \\
\hline 5. Project Cost (PC) & $\begin{array}{l}\text { It refers to that allows decision makers to compare different } \\
\text { projects in terms on how much money it is required to } \\
\text { complete the project. }\end{array}$ \\
\hline 6. Impact on area development (IAD) & $\begin{array}{l}\text { It refers to that allows decision makers to compare different } \\
\text { projects to determine the point area is now and the point } \\
\text { the area will reach in the future. }\end{array}$ \\
\hline 7. Maintenance cost per year (MC) & $\begin{array}{l}\text { It refers to that allows decision makers to compare different } \\
\text { projects in terms on how much money it is required to } \\
\text { maintenance per year for the project. }\end{array}$ \\
\hline
\end{tabular}


Nine potential main municipal projects, MMPs, -MMP1, MMP2, MMP3, ... , MMP9 are involved for evaluation. The hierarchical structure of the decision problem is represented in Figure 2.

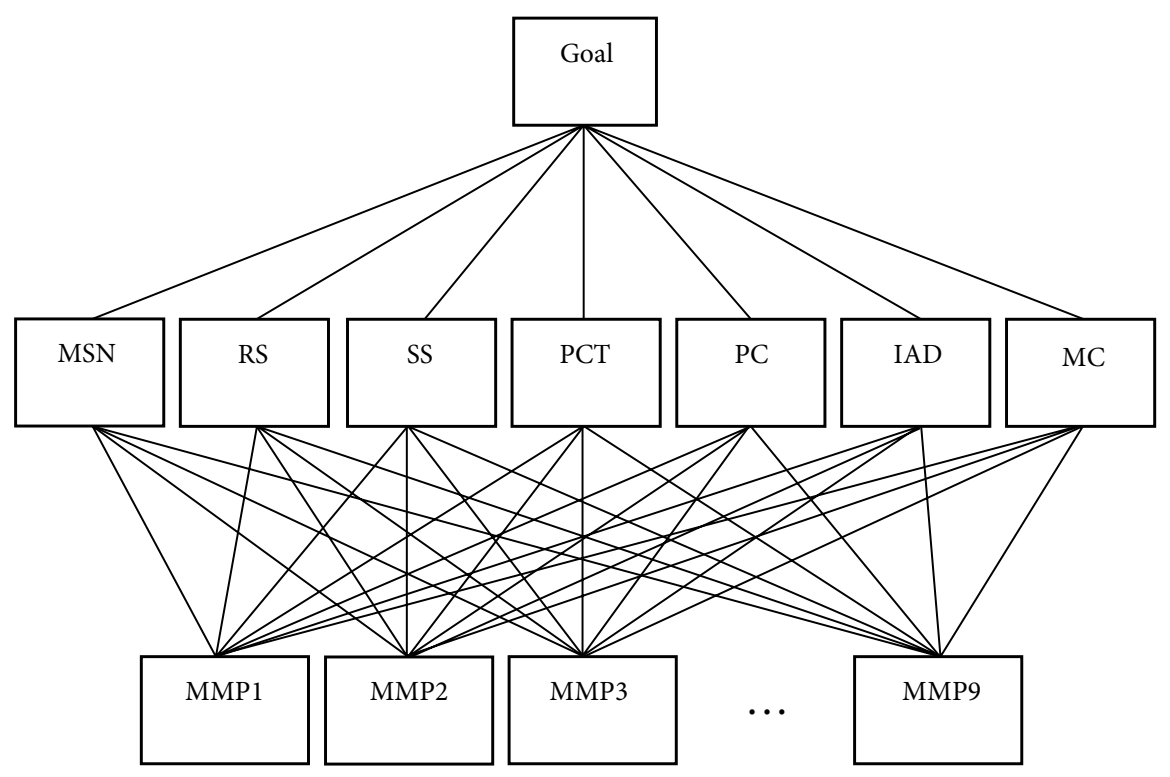

Fig. 2. Hierarchical structure of decision problem

The fuzzy TOPSIS methodology is used to rank main municipal projects in the first stage of the proposed methodology. For this aim, three experts, E1, E2, and E3, from the municipality (one strategic planning coordinator, one coordinator and one industrial engineer) are chosen for the determination and evaluation of criteria. The linguistic scale for this evaluation is shown in Table 6.

The criteria weights for TOPSIS are determined as shown in Table 7.

Table 6. The linguistic evaluation of criteria

\begin{tabular}{llll}
\hline & E1 & E2 & E3 \\
\hline MSN & VH & H & H \\
\hline RS & L & VL & ML \\
\hline SS & M & MH & M \\
\hline PCT & H & MH & MH \\
\hline PC & M & ML & ML \\
\hline IAD & ML & L & L \\
\hline MC & MH & M & M \\
\hline
\end{tabular}

Table 7. The weights of criteria

\begin{tabular}{lc}
\hline MSN & $(0.767,0.933,1)$ \\
\hline RS & $(0.033,0.133,0.3)$ \\
\hline SS & $(0.367,0.567,0.767)$ \\
\hline PCT & $(0.567,0.767,0.933)$ \\
\hline PC & $(0.167,0.367,0.567)$ \\
\hline IAD & $(0.033,0.167,0.367)$ \\
\hline MC & $(0.367,0.567,0.767)$ \\
\hline
\end{tabular}


The decision-makers use the linguistic variables to evaluate the ratings of alternatives with respect to each criterion and these evaluations are shown in Table 8. Then the fuzzy decision matrix is obtained and fuzzy weights of alternatives are shown in Table 9. The normalized fuzzy decision matrix and the weighted normalized fuzzy decision matrix are obtained as shown in Tables 10 and 11, respectively.

Table 8 . The rating of alternatives

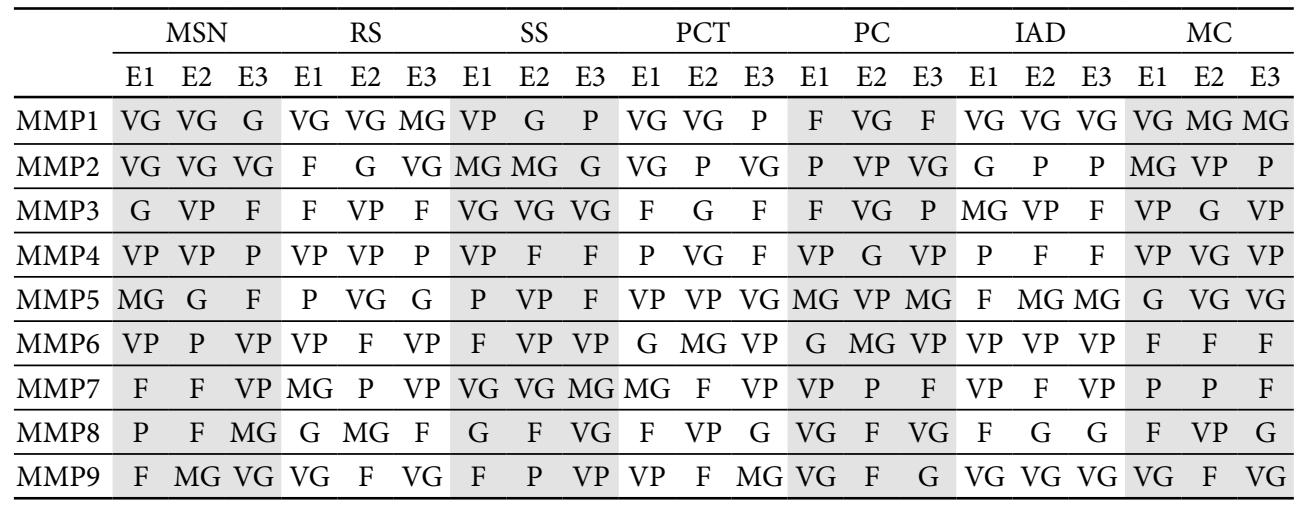

Table 9. The fuzzy decision matrix and fuzzy weights of alternatives

\begin{tabular}{|c|c|c|c|c|c|c|c|c|c|c|c|c|}
\hline & \multicolumn{3}{|c|}{ MSN } & \multicolumn{3}{|c|}{ RS } & \multicolumn{3}{|c|}{ SS } & \multicolumn{3}{|c|}{ PCT } \\
\hline MMP1 & 8.33 & 9.67 & 10.00 & 7.67 & 9.00 & 9.67 & 2.33 & 3.33 & 4.67 & 6.00 & 7.00 & 7.67 \\
\hline MMP2 & 9.00 & 10.00 & 10.00 & 5.67 & 7.33 & 8.33 & 5.67 & 7.67 & 9.33 & 6.00 & 7.00 & 7.67 \\
\hline MMP3 & 2.67 & 4.00 & 5.33 & 0.67 & 2.00 & 3.67 & 9.00 & 10.00 & 10.00 & 3.00 & 5.00 & 6.67 \\
\hline MMP4 & 0.00 & 0.33 & 1.67 & 0.00 & 0.33 & 1.67 & 0.67 & 2.00 & 3.67 & 3.33 & 4.67 & 6.00 \\
\hline MMP5 & 4.33 & 6.33 & 8.00 & 5.33 & 6.67 & 7.67 & 0.33 & 1.33 & 3.00 & 3.00 & 3.33 & 4.00 \\
\hline MMP6 & 0.00 & 0.33 & 1.67 & 0.33 & 1.00 & 2.33 & 0.33 & 1.00 & 2.33 & 4.00 & 5.33 & 6.67 \\
\hline MMP7 & 0.67 & 2.00 & 3.67 & 1.67 & 2.67 & 4.33 & 7.67 & 9.00 & 9.67 & 2.00 & 3.33 & 5.00 \\
\hline MMP8 & 2.00 & 3.67 & 5.67 & 4.33 & 6.33 & 8.00 & 5.67 & 7.33 & 8.33 & 2.67 & 4.00 & 5.33 \\
\hline \multirow[t]{2}{*}{ MMP9 } & 5.00 & 6.67 & 8.00 & 6.33 & 7.67 & 8.33 & 0.33 & 1.33 & 3.00 & 2.00 & 3.33 & 5.00 \\
\hline & & PC & & & IAD & & & $\mathrm{MC}$ & & & & \\
\hline MMP1 & 3.67 & 5.33 & 6.67 & 9.00 & 10.00 & 10.00 & 6.33 & 8.00 & 9.33 & & & \\
\hline MMP2 & 3.00 & 3.67 & 4.67 & 2.33 & 3.67 & 5.33 & 1.67 & 2.67 & 4.33 & & & \\
\hline MMP3 & 3.33 & 4.67 & 6.00 & 2.00 & 3.33 & 5.00 & 2.33 & 3.00 & 4.00 & & & \\
\hline MMP4 & 2.33 & 3.00 & 4.00 & 0.67 & 2.33 & 4.33 & 3.00 & 3.33 & 4.00 & & & \\
\hline MMP5 & 3.33 & 4.67 & 6.33 & 3.67 & 5.67 & 7.67 & 8.33 & 9.67 & 10.00 & & & \\
\hline MMP6 & 4.00 & 5.33 & 6.67 & 0.00 & 0.00 & 1.00 & 1.00 & 3.00 & 5.00 & & & \\
\hline MMP7 & 0.33 & 1.33 & 3.00 & 0.33 & 1.00 & 2.33 & 0.33 & 1.67 & 3.67 & & & \\
\hline MMP8 & 6.33 & 7.67 & 8.33 & 5.00 & 7.00 & 8.33 & 2.67 & 4.00 & 5.33 & & & \\
\hline MMP9 & 5.67 & 7.33 & 8.33 & 9.00 & 10.00 & 10.00 & 6.33 & 7.67 & 8.33 & & & \\
\hline
\end{tabular}


Table 10. The fuzzy normalized decision matrix

\begin{tabular}{|c|c|c|c|c|c|c|c|c|c|c|c|c|}
\hline & \multicolumn{3}{|c|}{ MSN } & \multicolumn{3}{|c|}{ RS } & \multicolumn{3}{|c|}{ SS } & \multicolumn{3}{|c|}{ PCT } \\
\hline MMP1 & 0.83 & 0.97 & 1.00 & 0.79 & 0.93 & 1.00 & 0.23 & 0.33 & 0.47 & 0.78 & 0.91 & 1.00 \\
\hline MMP2 & 0.90 & 1.00 & 1.00 & 0.59 & 0.76 & 0.86 & 0.57 & 0.77 & 0.93 & 0.78 & 0.91 & 1.00 \\
\hline MMP3 & 0.27 & 0.40 & 0.53 & 0.07 & 0.21 & 0.38 & 0.90 & 1.00 & 1.00 & 0.39 & 0.65 & 0.87 \\
\hline MMP4 & 0.00 & 0.03 & 0.17 & 0.00 & 0.03 & 0.17 & 0.07 & 0.20 & 0.37 & 0.43 & 0.61 & 0.78 \\
\hline MMP5 & 0.43 & 0.63 & 0.80 & 0.55 & 0.69 & 0.79 & 0.03 & 0.13 & 0.30 & 0.39 & 0.43 & 0.52 \\
\hline MMP6 & 0.00 & 0.03 & 0.17 & 0.03 & 0.10 & 0.24 & 0.03 & 0.10 & 0.23 & 0.52 & 0.70 & 0.87 \\
\hline MMP7 & 0.07 & 0.20 & 0.37 & 0.17 & 0.28 & 0.45 & 0.77 & 0.90 & 0.97 & 0.26 & 0.43 & 0.65 \\
\hline MMP8 & 0.20 & 0.37 & 0.57 & 0.45 & 0.66 & 0.83 & 0.57 & 0.73 & 0.83 & 0.35 & 0.52 & 0.70 \\
\hline \multirow[t]{2}{*}{ MMP9 } & 0.50 & 0.67 & 0.80 & 0.66 & 0.79 & 0.86 & 0.03 & 0.13 & 0.30 & 0.26 & 0.43 & 0.65 \\
\hline & & $\mathrm{PC}$ & & & IAD & & & $\mathrm{MC}$ & & & & \\
\hline MMP1 & 0.44 & 0.64 & 0.80 & 0.90 & 1.00 & 1.00 & 0.63 & 0.80 & 0.93 & & & \\
\hline MMP2 & 0.36 & 0.44 & 0.56 & 0.23 & 0.37 & 0.53 & 0.17 & 0.27 & 0.43 & & & \\
\hline MMP3 & 0.40 & 0.56 & 0.72 & 0.20 & 0.33 & 0.50 & 0.23 & 0.30 & 0.40 & & & \\
\hline MMP4 & 0.28 & 0.36 & 0.48 & 0.07 & 0.23 & 0.43 & 0.30 & 0.33 & 0.40 & & & \\
\hline MMP5 & 0.40 & 0.56 & 0.76 & 0.37 & 0.57 & 0.77 & 0.83 & 0.97 & 1.00 & & & \\
\hline MMP6 & 0.48 & 0.64 & 0.80 & 0.00 & 0.00 & 0.10 & 0.10 & 0.30 & 0.50 & & & \\
\hline MMP7 & 0.04 & 0.16 & 0.36 & 0.03 & 0.10 & 0.23 & 0.03 & 0.17 & 0.37 & & & \\
\hline MMP8 & 0.76 & 0.92 & 1.00 & 0.50 & 0.70 & 0.83 & 0.27 & 0.40 & 0.53 & & & \\
\hline MMP9 & 0.68 & 0.88 & 1.00 & 0.90 & 1.00 & 1.00 & 0.63 & 0.77 & 0.83 & & & \\
\hline
\end{tabular}

Table 11. The fuzzy weighted normalized decision matrix

\begin{tabular}{|c|c|c|c|c|c|c|c|c|c|c|c|c|}
\hline & \multicolumn{3}{|c|}{ MSN } & \multicolumn{3}{|c|}{ RS } & \multicolumn{3}{|c|}{ SS } & \multicolumn{3}{|c|}{ PCT } \\
\hline MMP1 & 0.64 & 0.90 & 1.00 & 0.03 & 0.12 & 0.30 & 0.09 & 0.19 & 0.36 & 0.44 & 0.70 & 0.93 \\
\hline MMP2 & 0.69 & 0.93 & 1.00 & 0.02 & 0.10 & 0.26 & 0.21 & 0.43 & 0.72 & 0.44 & 0.70 & 0.93 \\
\hline MMP3 & 0.20 & 0.37 & 0.53 & 0.00 & 0.03 & 0.11 & 0.33 & 0.57 & 0.77 & 0.22 & 0.50 & 0.81 \\
\hline MMP4 & 0.00 & 0.03 & 0.17 & 0.00 & 0.00 & 0.05 & 0.02 & 0.11 & 0.28 & 0.25 & 0.47 & 0.73 \\
\hline MMP5 & 0.33 & 0.59 & 0.80 & 0.02 & 0.09 & 0.24 & 0.01 & 0.08 & 0.23 & 0.22 & 0.33 & 0.49 \\
\hline MMP6 & 0.00 & 0.03 & 0.17 & 0.00 & 0.01 & 0.07 & 0.01 & 0.06 & 0.18 & 0.30 & 0.53 & 0.81 \\
\hline MMP7 & 0.05 & 0.19 & 0.37 & 0.01 & 0.04 & 0.13 & 0.28 & 0.51 & 0.74 & 0.15 & 0.33 & 0.61 \\
\hline MMP8 & 0.15 & 0.34 & 0.57 & 0.01 & 0.09 & 0.25 & 0.21 & 0.42 & 0.64 & 0.20 & 0.40 & 0.65 \\
\hline \multirow[t]{2}{*}{ MMP9 } & 0.38 & 0.62 & 0.80 & 0.02 & 0.11 & 0.26 & 0.01 & 0.08 & 0.23 & 0.15 & 0.33 & 0.61 \\
\hline & & $\mathrm{PC}$ & & & IAD & & & $\mathrm{MC}$ & & & & \\
\hline MMP1 & 0.07 & 0.23 & 0.45 & 0.03 & 0.17 & 0.37 & 0.23 & 0.45 & 0.72 & & & \\
\hline MMP2 & 0.06 & 0.16 & 0.32 & 0.01 & 0.06 & 0.20 & 0.06 & 0.15 & 0.33 & & & \\
\hline MMP3 & 0.07 & 0.21 & 0.41 & 0.01 & 0.06 & 0.18 & 0.09 & 0.17 & 0.31 & & & \\
\hline MMP4 & 0.05 & 0.13 & 0.27 & 0.00 & 0.04 & 0.16 & 0.11 & 0.19 & 0.31 & & & \\
\hline MMP5 & 0.07 & 0.21 & 0.43 & 0.01 & 0.09 & 0.28 & 0.31 & 0.55 & 0.77 & & & \\
\hline MMP6 & 0.08 & 0.23 & 0.45 & 0.00 & 0.00 & 0.04 & 0.04 & 0.17 & 0.38 & & & \\
\hline MMP7 & 0.01 & 0.06 & 0.20 & 0.00 & 0.02 & 0.09 & 0.01 & 0.09 & 0.28 & & & \\
\hline MMP8 & 0.13 & 0.34 & 0.57 & 0.02 & 0.12 & 0.31 & 0.10 & 0.23 & 0.41 & & & \\
\hline MMP9 & 0.11 & 0.32 & 0.57 & 0.03 & 0.17 & 0.37 & 0.23 & 0.43 & 0.64 & & & \\
\hline
\end{tabular}


The distances of each project from FPIS and FNIS are calculated and they are shown in Tables 12 and 13, respectively.

In the last step, the closeness coefficient of each alternative is calculated as shown in Table 14.

Table 12. The distance measurements from FPIS

\begin{tabular}{ccccccccc}
\hline & MSN & RS & SS & PCT & PC & IAD & MC & A $^{*}$ \\
\hline MMP1 & 0.216 & 0.857 & 0.797 & 0.367 & 0.762 & 0.824 & 0.568 & 4.392 \\
\hline MMP2 & 0.183 & 0.879 & 0.585 & 0.367 & 0.827 & 0.915 & 0.826 & 4.584 \\
\hline MMP3 & 0.644 & 0.953 & 0.480 & 0.545 & 0.786 & 0.921 & 0.818 & 5.147 \\
\hline MMP4 & 0.937 & 0.982 & 0.867 & 0.555 & 0.855 & 0.936 & 0.802 & 5.933 \\
\hline MMP5 & 0.467 & 0.889 & 0.899 & 0.662 & 0.780 & 0.878 & 0.497 & 5.071 \\
\hline MMP6 & 0.937 & 0.971 & 0.920 & 0.500 & 0.760 & 0.988 & 0.816 & 5.892 \\
\hline MMP7 & 0.809 & 0.943 & 0.524 & 0.664 & 0.914 & 0.966 & 0.878 & 5.698 \\
\hline MMP8 & 0.668 & 0.889 & 0.605 & 0.613 & 0.681 & 0.862 & 0.766 & 5.084 \\
\hline MMP9 & 0.433 & 0.877 & 0.899 & 0.664 & 0.691 & 0.824 & 0.589 & 4.977 \\
\hline
\end{tabular}

Table 13. The distance measurements from FNIS

\begin{tabular}{lcccccccc}
\hline & MSN & RS & SS & PCT & PC & IAD & MC & A- \\
\hline MMP1 & 0.861 & 0.188 & 0.239 & 0.721 & 0.298 & 0.233 & 0.507 & 3.046 \\
\hline MMP2 & 0.885 & 0.161 & 0.498 & 0.721 & 0.208 & 0.118 & 0.214 & 2.804 \\
\hline MMP3 & 0.394 & 0.068 & 0.582 & 0.565 & 0.267 & 0.111 & 0.208 & 2.195 \\
\hline MMP4 & 0.098 & 0.030 & 0.176 & 0.520 & 0.177 & 0.094 & 0.217 & 1.312 \\
\hline MMP5 & 0.605 & 0.148 & 0.140 & 0.364 & 0.278 & 0.171 & 0.572 & 2.278 \\
\hline MMP6 & 0.098 & 0.043 & 0.109 & 0.586 & 0.298 & 0.021 & 0.243 & 1.398 \\
\hline MMP7 & 0.239 & 0.081 & 0.544 & 0.410 & 0.123 & 0.050 & 0.171 & 1.618 \\
\hline MMP8 & 0.392 & 0.152 & 0.456 & 0.455 & 0.388 & 0.189 & 0.276 & 2.308 \\
\hline MMP9 & 0.626 & 0.162 & 0.140 & 0.410 & 0.382 & 0.233 & 0.466 & 2.418 \\
\hline
\end{tabular}

Table 14. The closeness coefficient of each alternative

\begin{tabular}{lccccccccc}
\hline & MMP1 & MMP2 & MMP3 & MMP4 & MMP5 & MMP6 & MMP7 & MMP8 & MMP9 \\
\hline$C C_{i}$ & 0.40952 & 0.37958 & 0.29894 & 0.1811 & 0.31002 & 0.19174 & 0.22116 & 0.31224 & 0.327 \\
\hline Rank & 1 & 2 & 6 & 9 & 5 & 8 & 7 & 4 & 3 \\
\hline
\end{tabular}

According to Table 14, MMP1 (Urban development projects) is determined as the best alternative among municipality projects and the ranking of alternative is determined as \{MMP1-MMP2-MMP9-MMP8-MMP5-MMP3-MMP7-MMP6-MMP4\}.

In the second phase, the best project alternative named "Urban development projects (MMP1)" is analyzed and the ranking of four sub-municipal projects for this alternative are prioritized by using fuzzy AHP. The weights of the criteria are obtained in the first phase of the application by using TOPSIS and they are used as shown in Table 7 . These weights are 
defuzzified and normalized to be used in fuzzy AHP phase. After the weights of the criteria are determined, the alternatives are evaluated with respect to the criteria. For example, the linguistic evaluations of three decision makers for alternatives with respect to the criteria "Impact on area development (IAD)", are shown in Table 15. These evaluations are converted to the fuzzy numbers as shown in Table 16.

All of the alternatives are evaluated with respect to 7 criteria by DMs. The obtained results are summarized in Table 17. According to Table 17, the alternative project "Projects for infrastructure (1.1)" is determined as the best alternative. The rank of the alternatives is as follows: $\{1.1-1.2-1.4-1.3\}$. This means Projects for infrastructure (1.1) has the largest priority with 0.407 . Projects for urban transformation (1.2) has the second priority with 0.2226 . Projects for enabling housing audits has the third priority and Projects for supporting aesthetical aspects of the city does the forth.

Table 15. DMs' Evaluation for Alternative with respect to C11

\begin{tabular}{lllllllllllll}
\hline & \multicolumn{3}{c}{ E1 } & \multicolumn{1}{c}{ E2 } & \multicolumn{1}{c}{ E3 } \\
\cline { 2 - 12 } & 1.1 & 1.2 & 1.3 & 1.4 & 1.1 & 1.2 & 1.3 & 1.4 & 1.1 & 1.2 & 1.3 & 1.4 \\
\hline 1.1 & & Wk & Es & Vs & & Eq & Wk & Es & & Eq & Es & Vs \\
\hline 1.2 & & Es & Vs & & & Es & Es & & Eq & Eq \\
\hline 1.3 & & & Es & & & & Vs & & & Vs \\
\hline 1.4 & & & & & & & & & & & & \\
\hline
\end{tabular}

Table 16. Converted fuzzy numbers of experts evaluations for alternatives

\begin{tabular}{|c|c|c|c|c|}
\hline & \multicolumn{4}{|c|}{ E1 } \\
\hline & 1.1 & 1.2 & 1.3 & 1.4 \\
\hline 1.1 & & $(1,3,5)$ & $(3,5,7)$ & $(5,7,9)$ \\
\hline 1.2 & $(0.2,0.333,1)$ & & $(3,5,7)$ & $(5,7,9)$ \\
\hline 1.3 & $(0.143,0.2,0.333)$ & $(0.143,0.2,0.333)$ & & $(3,5,7)$ \\
\hline \multirow[t]{3}{*}{1.4} & $(0.111,0.143,0.2)$ & $(0.111,0.143,0.2)$ & $(0.143,0.2,0.333)$ & \\
\hline & & $\mathrm{E} 2$ & & \\
\hline & 1.1 & 1.2 & 1.3 & 1.4 \\
\hline 1.1 & & $(1,1,3)$ & $(1,3,5)$ & $(3,5,7)$ \\
\hline 1.2 & $(0.333,1,1)$ & & $(3,5,7)$ & $(3,5,7)$ \\
\hline 1.3 & $(0.2,0.333,1)$ & $(0.143,0.2,0.333)$ & & $(5,7,9)$ \\
\hline \multirow[t]{3}{*}{1.4} & $(0.143,0.2,0.333)$ & $(0.143,0.2,0.333)$ & $(0.111,0.143,0.2)$ & \\
\hline & & E3 & & \\
\hline & $\overline{1.1}$ & 1.2 & 1.3 & 1.4 \\
\hline 1.1 & & $(1,1,3)$ & $(3,5,7)$ & $(5,7,9)$ \\
\hline 1.2 & $(0.333,1,1)$ & & $(1,1,3)$ & $(1,1,3)$ \\
\hline 1.3 & $(0.143,0.2,0.333)$ & $(0.333,1,1)$ & & $(5,7,9)$ \\
\hline 1.4 & $(0.111,0.143,0.2)$ & $(0.333,1,1)$ & $(0.111,0.143,0.2)$ & \\
\hline
\end{tabular}


A sensitivity analysis is realized to see how the rank order of the alternatives behave when the weight of the criteria are changed. In other words, we want to see how sensitive our decision to the changes in the criteria weights. The cases shown in Table 18 are taken into account. Notice that the first case is the one we have already studied above.

These cases in Table 18 are analyzed and the results are summarized in Figure 3.

Table 17. The evaluation results for alternatives

\begin{tabular}{ccccccccc}
\hline & MSN & RS & SS & PCT & PC & IAD & MC & \\
\hline Alternatives & $\mathbf{0 . 2 2 5}$ & $\mathbf{0 . 0 5 4}$ & $\mathbf{0 . 1 6 5}$ & $\mathbf{0 . 2 1 0}$ & $\mathbf{0 . 1 1 5}$ & $\mathbf{0 . 0 6 6}$ & $\mathbf{0 . 1 6 5}$ & $\boldsymbol{w}$ \\
\hline 1.1 & 0.594 & 0.605 & 0.605 & 0.104 & 0.104 & 0.479 & 0.460 & $\mathbf{0 . 4 0 7}$ \\
\hline 1.2 & 0.279 & 0.270 & 0.270 & 0.063 & 0.063 & 0.307 & 0.385 & $\mathbf{0 . 2 2 6}$ \\
\hline 1.3 & 0.089 & 0.091 & 0.091 & 0.358 & 0.358 & 0.159 & 0.094 & $\mathbf{0 . 1 8 2}$ \\
\hline 1.4 & 0.038 & 0.034 & 0.034 & 0.475 & 0.475 & 0.055 & 0.061 & $\mathbf{0 . 1 8 4}$ \\
\hline
\end{tabular}

Table 18. The cases considered for sensitivity analysis

\begin{tabular}{lccccccc}
\hline & \multicolumn{7}{c}{ Weights of Criteria } \\
\cline { 2 - 8 } & MSN & RS & SS & PCT & PC & IAD & MC \\
\hline Case-I & 0.23 & 0.05 & 0.16 & 0.21 & 0.12 & 0.07 & 0.16 \\
\hline Case-II & 0.70 & 0.05 & 0.05 & 0.05 & 0.05 & 0.05 & 0.05 \\
\hline Case-III & 0.05 & 0.05 & 0.05 & 0.70 & 0.05 & 0.05 & 0.05 \\
\hline Case-IV & 0.05 & 0.05 & 0.05 & 0.05 & 0.05 & 0.70 & 0.05 \\
\hline Case-V & 0.05 & 0.05 & 0.05 & 0.375 & 0.375 & 0.05 & 0.05 \\
\hline
\end{tabular}

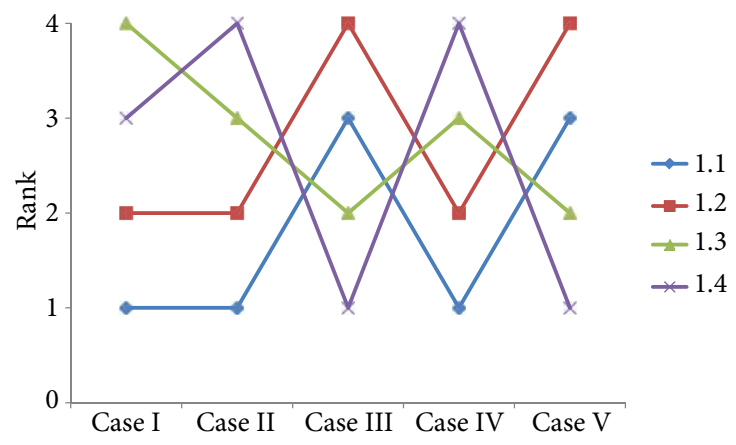

Fig. 3. The results of sensitivity analysis

According to Figure 3, the ranking of the alternatives for Case II is very close to obtained results in the application. "Projects for infrastructure (1.1)" and "Projects for urban transformation (1.2)" are the two best alternatives. In Case-III, "Projects for enabling housing audits (1.4)" is determined as the best alternative while "Projects for urban transformation (1.2)" becomes the worst alternative and "Projects for infrastructure (1.1)" becomes the third alternative. As the weight of the criterion PCT or PC increases, "Projects for enabling housing audits (1.4)" moves to be the best alternative. 


\section{Conclusions and future research}

The municipalities should support citizens, industrial firms, households etc. to find their own way and contributions to a more sustainable behavior such as regarding production, consumption, waste, traffic and nature protection. Hence project selection and prioritization are very important for municipalities. In this paper, a two phased fuzzy methodology is proposed. In the first phase fuzzy TOPSIS method is used to select the main project group and then fuzzy AHP is used to select the best sub-municipal project. The application is made in the central district municipality in Konya, Turkey. The best project alternative is determined as "Urban development projects". It means that Konya Metropolitan Municipality should give the first priority to the investment for "urban development". Sub-municipal projects for this alternative are prioritized by using fuzzy AHP and the sub-project alternative "Projects for infrastructure" is determined as the best alternative. The rank of the sub-project alternatives is determined as follows: "Projects for infrastructure"; "Projects for urban transformation"; "Projects for enabling housing audits"; "Projects for supporting aesthetical aspects of the city".

For the future research, the other MCDM methodologies such as VIKOR, PROMETHEE etc. can be used for selection among municipal projects and the obtained results can be compared with ours.

\section{References}

Aydın, S.; Kahraman, C.; Kaya, İ. 2012. A new fuzzy multicriteria decision making approach: an application for European quality award assessment, Knowledge Based Systems 32: 37-46. http://dx.doi.org/10.1016/j.knosys.2011.08.022

Buckley, J. J. 1985. Fuzzy hierarchical analysis, Fuzzy Sets and Systems 17(3): 233-247. http://dx.doi.org/10.1016/0165-0114(85)90090-9

Chen, S. J.; Hwang, C. L. 1992. Fuzzy multiple attribute decision making: methods and applications. Berlin: Springer-Verlag. 536 p. http://dx.doi.org/10.1007/978-3-642-46768-4

Chen, T. C. 2000. Extensions of the TOPSIS for group decision-making under fuzzy environment, Fuzzy Sets and Systems 114(1): 1-9. http://dx.doi.org/10.1016/S0165-0114(97)00377-1

Gamberini, R.; Grassi, A.; Rimini, B. 2006. A new multi-objective heuristic algorithm for solving the stochastic assembly line re-balancing problem, International Journal of Production Economics 102(2): 226-243. http://dx.doi.org/10.1016/j.ijpe.2005.02.013

Hsieh, T. Y.; Lu, S. T.; Tzeng, G. H. 2004. Fuzzy MCDM approach for planning and design tenders selection in public office buildings, International Journal of Project Management 22(7): 573-584. http://dx.doi.org/10.1016/j.ijproman.2004.01.002

Hwang, C. L.; Yoon, K. 1981. Multiple attributes decision making methods and applications. Berlin Heidelberg: Springer. http://dx.doi.org/10.1007/978-3-642-48318-9

Kahraman, C.; Beskese, A.; Ruan, D. 2004b. Measuring flexibility of computer integrated manufacturing systems using fuzzy cash flow analysis, Information Sciences 168(1-4): 77-94. http://dx.doi.org/10.1016/j.ins.2003.11.004

Kahraman, C.; Cebeci, A.; Ruan, D. 2004a. Multi-attribute comparison of catering service companies using fuzzy AHP: the case of Turkey, International Journal of Production Economics 87(2): 171-184. http://dx.doi.org/10.1016/S0925-5273(03)00099-9 
Kahraman, C.; Engin, O.; Kabak, O.; Kaya, I. 2009b. Information systems outsourcing decisions using a group decision-making approach, Engineering Applications of Artificial Intelligence 22(6): 832-841. http://dx.doi.org/10.1016/j.engappai.2008.10.009

Kahraman, C.; Kaya, I. 2010. A fuzzy multicriteria methodology for selection among energy alternatives, Expert Systems with Applications 37(9): 6270-6281. http://dx.doi.org/10.1016/j.eswa.2010.02.095

Kahraman, C.; Kaya, I.; Cebi, S. 2009a. A comparative analysis for multiattribute selection among renewable energy alternatives using fuzzy axiomatic design and fuzzy analytic hierarchy process, Energy 34(10): 1603-1616. http://dx.doi.org/10.1016/j.energy.2009.07.008

Kahraman, C.; Süder, A.; Kaya, İ. 2013. Fuzzy multicriteria evaluation of health research investments, Technological and Economic Development of Economy 20(2): 210-226. http://dx.doi.org/10.3846/20294913.2013.876560

Kaya, İ. 2012. Evaluation of outsourcing alternatives under fuzzy environment for waste management, Resources, Conservation and Recycling 60: 107-118. http://dx.doi.org/10.1016/j.resconrec.2011.12.006

Kılıç, H. S. 2011. A fuzzy AHP based performance assessment system for the strategic plan of Turkish municipalities, International Journal of Business and Management Studies 3(2): 77-86.

Liou, T. S.; Wang, M. J. 1992. Ranking fuzzy numbers with integral value, Fuzzy Sets and Systems 50(3): 247-255. http://dx.doi.org/10.1016/0165-0114(92)90223-Q

Mahmoodzadeh, S.; Shahrabi, J.; Pariazar, M.; Zaeri, M. S. 2007. Project selection by using fuzzy AHP and TOPSIS technique, World Academy of Science, Engineering and Technology 30: 333-338.

Saaty, T. L. 1980. Multicriteria decision making: the analytic hierarchy process. Pittsburgh, PA: RWS Publications.

Sadeghi Moghaddam, M. R.; Yavari, A.; Ghariblu, F.; Anbari, Y. 2011. Ranking of strategic management indicators in improvement of urban management by using multiple attribute decision method of TOPSIS, Applied Mechanics and Materials 99-100: 524-530.

Smith-Perera, A.; Garcia-Melon, M.; Poveda-Bautista, R.; Pastor-Ferrando, J. P. 2010. A project strategic index proposal for portfolio selection in electrical company based on the analytic network process, $R e$ newable and Sustainable Energy Reviews 14(6): 1569-1579. http://dx.doi.org/10.1016/j.rser.2010.01.022

TUIK. 2010. Address based population registration system population census [online], [cited 11 March 2012]. Available from Internet: http://www.tuik.gov.tr

Xiao, X. Y.; Yang, L.W. 2011. A comparative study of regional innovation capability of China based on TOPSIS method, in International Conference on Business Management and Electronic Information (BMEI), 13-15 May 2011, Guangzhou, 579-582. http://dx.doi.org/10.1109/ICBMEI.2011.5917977

Yoon, K. P.; Hwang, C. L. 1995. Multiple attribute decision making: an introduction. Sage publications. 75 p.

Zeng, G.; Jiang, R.; Huang, G.; Xu, M.; Li, J. 2007. Optimization of wastewater treatment alternative selection by hierarchy grey relational analysis, Journal of Environmental Management 82(2): 250-259. http://dx.doi.org/10.1016/j.jenvman.2005.12.024

Mehmet Emin BAYSAL. He received BS from Istanbul Technical University on Industrial Engineering and MSc degrees in Industrial Engineering from Gazi University. He also received $\mathrm{PhD}$ degree from Gazi University on Industrial Engineering. He is currently an Assistant Professor, Dr at Selçuk University Department of Industrial Engineering. His main research interests include performance measurement, linear optimization and multicriteria decision making, and fuzzy sets applications.

İhsan KAYA. He received BS and MSc degrees in Industrial Engineering from Selcuk University. He also received $\mathrm{PhD}$ degree from Istanbul Technical University on Industrial Engineering. Currently he is an Associate Professor, Dr at Ylldı Technical University Department of Industrial Engineering. He has published over 100 papers. His main research interests include process capability analysis, quality management and control, statistical and multicriteria decision making, and fuzzy sets applications. 
Cengiz KAHRAMAN. He is a Professor in Industrial Engineering Department at Istanbul Technical University. He published about 150 journal papers and about 120 conference papers. He is the Guest Editor of many international journals and the Editor of many international books from Springer and Atlantis Press. His research areas are engineering economics, quality control and management, statistical decision making, multicriteria decision making, and fuzzy decision making.

Ahmet SARUCAN. He received BS and MSc degrees in Industrial Engineering from Selcuk University. He received $\mathrm{PhD}$ degree from Gazi University on Industrial Engineering. He is currently an Assistant Professor, Dr at Selçuk University Department of Industrial Engineering. His main research interests include energy system planning, multicriteria decision making, and fuzzy sets applications.

Orhan ENGİN. He received BS, MSc and PhD degrees from Istanbul Technical University on Industrial Engineering. He is currently an Associate Professor, Dr at Selcuk University Department of Industrial Engineering. His main research interests include, scheduling, quality management and control, multicriteria decision making, and fuzzy sets applications. 